\title{
Effect of Different Calcination Temperatures on the Structural and Photocatalytic Performance of $\mathrm{Bi}^{-\mathrm{TiO}_{2}} / \mathrm{SBA}-15$
}

\author{
Jing Ma, ${ }^{1}$ Jia Chu, ${ }^{2}$ Liangsheng Qiang, ${ }^{3}$ and Juanqin $\mathrm{Xue}^{1}$ \\ ${ }^{1}$ College of Metallurgical Engineering, Xi'an University of Architecture and Technology, Xian 710055, China \\ ${ }^{2}$ College of Chemistry and Chemical Engineering, Xian University of Science and Technology, Xi'an 710054, China \\ ${ }^{3}$ Department of Chemistry, Harbin Institute of Technology, Harbin 150001, China
}

Correspondence should be addressed to Jing Ma; mjhit@yahoo.cn and Jia Chu; chujiahit@yahoo.cn

Received 17 May 2013; Revised 27 June 2013; Accepted 28 June 2013

Academic Editor: Huogen Yu

Copyright (C) 2013 Jing Ma et al. This is an open access article distributed under the Creative Commons Attribution License, which permits unrestricted use, distribution, and reproduction in any medium, provided the original work is properly cited.

\begin{abstract}
The new novel material $\mathrm{Bi}-\mathrm{TiO}_{2} / \mathrm{SBA}-15$ was synthesized by an easy wet impregnation method. A combination of XRD, XPS, Raman, $\mathrm{N}_{2}$ adsorption-desorption isotherm measurement, TEM, and solid state UV-Vis spectroscopy has been used to characterize the Bi$\mathrm{TiO}_{2} / \mathrm{SBA}-15$ material. It was found that SBA-15 retained the ordered hexagonal mesostructure after incorporation of $\mathrm{TiO}_{2}$ and $\mathrm{Bi}$. The photodecomposition of rhodamine $\mathrm{B}(\mathrm{RhB})$ in aqueous medium was selected to evaluate the photocatalytic performance of $\mathrm{Bi}$ $\mathrm{TiO}_{2} /$ SBA-15 under visible light irradiation $(\lambda \geq 420 \mathrm{~nm})$. The experiment results indicated that $\mathrm{Bi}^{-T i O}{ }_{2} / \mathrm{SBA}-15$ exhibited higher photocatalytic activities than pure $\mathrm{TiO}_{2}$ and $\mathrm{Bi}_{2} \mathrm{O}_{3}$. The influences of calcination temperature were studied. It strongly influenced the activity of the samples. The sample calcined at $550^{\circ} \mathrm{C}$ shows the highest photocatalytic activity in the decomposition of $\mathrm{RhB}$ under visible light. The catalyst preserved almost its initial photocatalytic activity after six reuses.
\end{abstract}

\section{Introduction}

The photocatalytic properties of $\mathrm{TiO}_{2}$ have been exploited in various applications since Fujishima and Honda reported a $\mathrm{TiO}_{2}$ photochemical electrode for splitting water in 1972 [1]. $\mathrm{TiO}_{2}$ is regarded as the most promising one for its high photocatalytic activity, chemical/photocorrosion stability, low cost, and environmental friendiness. However, the large band gap of $\mathrm{TiO}_{2}(3.20 \mathrm{eV})$ and low quantum efficiency restricts its wide application [2]. This factor can be minimized by doping of semiconductors such as $\mathrm{WO}_{3}, \mathrm{Bi}_{2} \mathrm{O}_{3}$, and $\mathrm{CdS}$, which could change the electronic properties of $\mathrm{TiO}_{2}$ [3-5]. Among them, Bi-based photocatalysts $\left(\mathrm{Bi}_{2} \mathrm{O}_{3}\right.$ or its related compounds) have attracted much attention. $\mathrm{Bi}_{2} \mathrm{O}_{3}(2.8 \mathrm{eV})$ exhibits good charge carrier mobility, in which species with lone electron pair forming $\mathrm{Bi}-\mathrm{O}$ polyhedra can act as electron trapping centers and hinder electron-hole pair recombination to improve the photoabsorptivity and photocatalytic activity $[6,7]$.

Recently, there are several works on the photocatalytic properties of $\mathrm{Bi}$-doped $\mathrm{TiO}_{2}$ materials under visible light irradiation [8-10]. Hou et al. used $\mathrm{Bi}_{2} \mathrm{O}_{3}$ quantum dots to enhance the photoactivity of $\mathrm{TiO}_{2}$ nanosheets with exposed (001) facets [11]. Di Camillo et al. reported that $\mathrm{Bi}$-doped $\mathrm{TiO}_{2}$ NFs have been deposited by electrospinning and showed very interesting photocatalytic properties [12]. Su et al. synthesized a new $\mathrm{TiO}_{2}$-based photocatalyst with both $\mathrm{B}$ doping and $\mathrm{Bi}_{2} \mathrm{O}_{3}$ coupling $\left(\mathrm{Bi}_{2} \mathrm{O}_{3} / \mathrm{TiO}_{2-x} \mathrm{~B}_{x}\right)$. The catalyst was used in degrading pentachlorophenol under visible light $(\lambda>$ $420 \mathrm{~nm}$ ) irradiation [13]. Li et al. reported the preparation of highly monodisperse spherical $\mathrm{Bi}$-doped $\mathrm{TiO}_{2}$. Their hybrid showed enhanced photocatalytic activity under visible light [14]. Shamaila et al. demonstrated an approach for the preparation of a mesoporous nanocrystalline $\mathrm{TiO}_{2}$ based on EISA method [15]. The catalyst showed the superior activity as compared to $\mathrm{M}-\mathrm{TiO}_{2}$ ( $\mathrm{M}$ refers to metal ion), Degussa P25, and impregnated Degussa P25 for the photodegradation of Methyl Orange (MO) and 2,4-dichlorophenol (2,4$\mathrm{DCP})$. Rengaraj and coworkers synthesized a $\mathrm{Bi}^{3+}$-doped $\mathrm{TiO}_{2}$ nanocatalyst. According to their results, the presence of $\mathrm{Bi}$ species in $\mathrm{TiO}_{2}$ catalysts substantially enhanced the photocatalytic degradation of methyl parathion under UV irradiation [16]. 
Generally, the present $\mathrm{Bi}_{2} \mathrm{O}_{3}-\mathrm{TiO}_{2}$ composite photocatalysts were limited by the low adsorption ability. To address this issue, much effort has been focused on enhancing the adsorption ability of the catalysts to improve their photocatalytic performance. Well-ordered mesoporous silica materials such as MCM-41 and SBA-15 have been widely used for adsorption, separation and catalysis [17-20]. SBA-15 is a type of uniform hexagonal pores and high surface area mesoporous material. Such type of highly interconnected mesostructured porous material is expected to allow the guest species to access the opened porous host easily. Design of photocatalysts modified by SBA-15 is a promising way to enhance high photocatalytic activity. However, no studies have attempted to establish a system consisting of a $\mathrm{Bi}_{2} \mathrm{O}_{3}$ $\mathrm{TiO}_{2}$ hybrid incorporated into mesoporous silica.

Herein, the aim of the present paper is to investigate the synthesis of size controlled $\mathrm{Bi}_{2} \mathrm{O}_{3}$ and $\mathrm{TiO}_{2}$ supported on mesostructured SBA-15. The photodegradation of $\mathrm{RhB}$ was employed to evaluate the photocatalytic activities of the $\mathrm{Bi}$ $\mathrm{TiO}_{2} / \mathrm{SBA}-15$, with a $300 \mathrm{~W}$ Xe lamp $(\lambda \geq 420 \mathrm{~nm})$ as the light source.

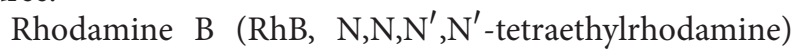
has moderate wash and light fastness properties. It is a useful analytical reagent for the detection and determination of metals. However, the use of RhB as a food color has been discontinued for a number of years on account of its suspected carcinogenic nature. Therefore, the removal of these dyes from wastewater is of great concern. Based on these considerations, the photodecomposition of $\mathrm{RhB}$ in aqueous medium was selected to evaluate the photocatalysis performance of $\mathrm{Bi}^{-} \mathrm{TiO}_{2} / \mathrm{SBA}-15$.

Considering the different calcination temperatures having an influence on the photocatalytic performance, the activities on different calcination temperatures were tested and discussed. Moreover, the recycle ability of $\mathrm{Bi}-\mathrm{TiO}_{2} / \mathrm{SBA}-$ 15 was also evaluated.

\section{Experimental}

2.1. Catalyst Preparations. The SBA- 15 was prepared according to the previous procedure by reaction from a solution of triblock copolymer P123 $\left(\mathrm{EO}_{20} \mathrm{PO}_{70} \mathrm{EO}_{20}\right.$, Aldrich) and tetraethoxysilane (TEOS) [21, 22]. P123 was used as a structure directing agent. In a typical process, $2 \mathrm{~g}$ of P123 was added to $75 \mathrm{~mL}$ of aqueous $\mathrm{HCl}$ under stirring at $40^{\circ} \mathrm{C}$ for 2h. $4.17 \mathrm{~mL}$ of TEOS was then added to the solution which was stirred for another $24 \mathrm{~h}$. The suspension was transferred into a steel autoclave and kept at $100^{\circ} \mathrm{C}$ for $72 \mathrm{~h}$. After cooling to room temperature, the precipitate in the bottom of Teflon vessel was collected, filtered, thoroughly washed with water to remove any unreacted chemicals, and dried at room temperature. Calcinations were performed by heating in air at $550^{\circ} \mathrm{C}$ for $6 \mathrm{~h}$ to remove the template.

$\mathrm{TiO}_{2} / \mathrm{SBA}-15$ material was first prepared by internal hydrolysis method with little modification [23]. In this case, the calculated amount of tetrabutyl titanate (TBT) was dissolved in ethanol in a volume ratio of $1: 5$ (the amount of TBT is $0.92 \mathrm{~mL}$ ). $0.5 \mathrm{~g}$ SBA- 15 was then added to the solution containing TBT and stirred for $1 \mathrm{~h}$ to make the TBT adsorb completely on the SBA-15. The condensation reaction was started by dropwise addition of water and then the stirring was continued for $2 \mathrm{~h}$ to hydrolyze TBT completely. The solid product was recovered by filtration, washed with ethanol to remove any unanchored titanium species, dried at $80^{\circ} \mathrm{C}$ overnight, and calcined in air at $550^{\circ} \mathrm{C}$ for $3 \mathrm{~h}$. The calcined samples were designated as $\mathrm{TiO}_{2} / \mathrm{SBA}-15$.

For Bi-doping $\mathrm{TiO}_{2} / \mathrm{SBA}-15$ supports, samples containing $\mathrm{Bi}$ were prepared by an easy wet impregnation method. $\mathrm{TiO}_{2} / \mathrm{SBA}-15$ and $\mathrm{Bi}\left(\mathrm{NO}_{3}\right)_{3} \cdot 5 \mathrm{H}_{2} \mathrm{O}$ were mixed in an ethanol solution with a drop of $\mathrm{HNO}_{3}$ and stirred for $5 \mathrm{~h}$, where the $\mathrm{Bi} / \mathrm{Ti}$ molar ratio is $2.0 \%$. The suspension was dried and calcined in air at different temperatures. The samples were designated as $\mathrm{Bi}-\mathrm{TiO}_{2} / \mathrm{SBA}-15(x)$, where $x$ refers to the calcination temperatures, which are $400^{\circ} \mathrm{C}, 550^{\circ} \mathrm{C}, 700^{\circ} \mathrm{C}$, and $850^{\circ} \mathrm{C}$, respectively.

2.2. Characterization Techniques. Small-angle X-ray diffraction (SAXRD) measurements were performed on a Siemens D5005 instrument with $\mathrm{CuK} \alpha(\lambda=0.154 \mathrm{~nm})$ radiation. The diffractograms were recorded in the 29 range of $0.5-5^{\circ}$ with a 29 step size of $0.01^{\circ}$. Wide-angle X-ray diffraction (WAXRD) measurements were carried out on an XRD-6000 X-ray diffractometer (Shimadzu) $\mathrm{CuK} \alpha(\lambda=0.154 \mathrm{~nm})$ radiation. The diffractograms were recorded in the 29 range of $10-80^{\circ}$ with a 29 step size of $0.2^{\circ}$. Raman spectra were measured with JOBIN YVON HR800 Raman spectrophotometer (France) in the range of $100-1400 \mathrm{~cm}^{-1}$, using an Ar ion laser. $\mathrm{N}_{2}$ adsorption-desorption isotherms were measured at $77 \mathrm{~K}$ in a Quantachrome Autosorb-1 sorption analyzer. Samples were outgassed at $300^{\circ} \mathrm{C}$ for $10 \mathrm{~h}$ before the measurement. TEM was performed by an FEI Tecnai G2 S-Twin electron microscope with an acceleration voltage of $200 \mathrm{kV}$. XPS was obtained using a physical electronics model PHI5700 $\mathrm{X}$-ray photoelectron spectrometer with $\mathrm{MgK} \alpha \mathrm{X}$-rays as the excitation source. The binding energies were calibrated with reference to $\mathrm{Cl}$ s at $285 \mathrm{eV}$. UV-V is absorption spectra scans were performed on a Shimadzu UV-2550 spectrometer in the range from 300 to $600 \mathrm{~nm}$. $\mathrm{BaSO}_{4}$ was used as a reflectance standard material during the experiment. Photoluminescence (PL) spectra were performed on JASCO FP6500 fluorescence spectrometer.

2.3. Photocatalytic Activity Measurement. The photocatalytic activities were investigated for the photodegradation of $\mathrm{RhB}$ in aqueous solution under visible light in a photolysis glass reactor. The $\mathrm{pH}$ of solution was 7 during the reaction. The visible light source was a $300 \mathrm{~W}$ Xe lamp ( $\lambda \geq 420 \mathrm{~nm}$ to provide visible light irradiation) with a double wall jacket in which water was circulated to prevent overheating of the reaction mixture. $50 \mathrm{mg}$ of $\mathrm{Bi}-\mathrm{TiO}_{2} / \mathrm{SBA}-15(x)$ was added to rhodamine $B(\mathrm{RhB})\left(100 \mathrm{~mL}, 1 \times 10^{-5} \mathrm{M}\right)$ and stirred for 30 min without visible light irradiation in order to establish an adsorption-desorption equilibrium between $\mathrm{RhB}$ and the catalyst. Next, the solution was illuminated by visible light. At a given time interval, $4 \mathrm{~mL}$ of the suspension was withdrawn. After centrifugation at $5000 \mathrm{rpm}$ for $5 \mathrm{~min}$, the filtrate was monitored by UV-Vis spectrophotometer (UV-5200). 


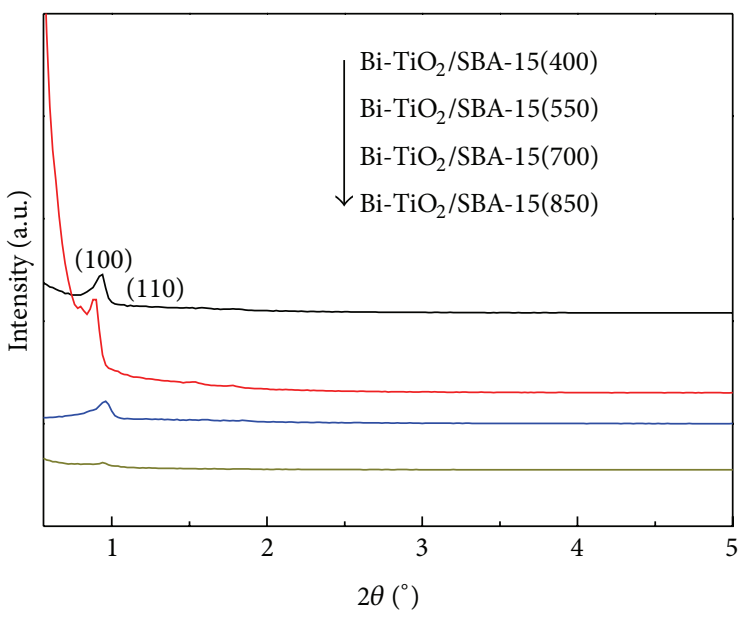

(a)

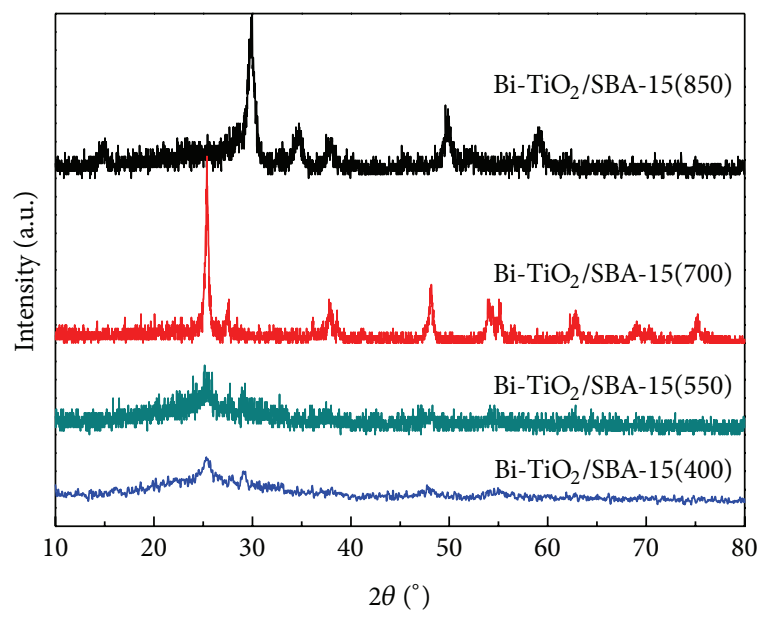

(b)

FIgURE 1: Small-angle (a) and wide-angle (b) XRD patterns of $\mathrm{Bi}^{-\mathrm{TiO}_{2}} / \mathrm{SBA}-15(x)$.

TABLE 1: Textural properties of $\mathrm{Bi}^{-\mathrm{TiO}_{2}} / \mathrm{SBA}-15(x)$.

\begin{tabular}{|c|c|c|c|c|}
\hline Samples & $\mathrm{Bi} / \mathrm{Ti}^{\mathrm{a}}$ & BET area $\left(\mathrm{m}^{2} \cdot \mathrm{g}^{-1}\right)$ & $V_{\text {tot }}{ }^{\mathrm{b}}\left(\mathrm{cm}^{3} \cdot \mathrm{g}^{-1}\right)$ & $D^{\mathrm{c}}(\mathrm{nm})$ \\
\hline SBA-15 & 0 & 590.3 & 0.961 & 7.224 \\
\hline $\mathrm{Bi}-\mathrm{TiO}_{2} / \mathrm{SBA}-15(400)$ & $2.01 \%$ & 540.1 & 0.544 & 5.936 \\
\hline $\mathrm{Bi}-\mathrm{TiO}_{2} / \mathrm{SBA}-15(550)$ & $1.95 \%$ & 527.7 & 0.518 & 5.882 \\
\hline $\mathrm{Bi}-\mathrm{TiO}_{2} / \mathrm{SBA}-15(700)$ & $1.89 \%$ & 299.5 & 0.307 & 5.767 \\
\hline $\mathrm{Bi}-\mathrm{TiO}_{2} / \mathrm{SBA}-15(850)$ & $1.62 \%$ & 182.7 & 0.221 & 4.061 \\
\hline $\mathrm{TiO}_{2} / \mathrm{SBA}-15(550)$ & 0 & 568.3 & 0.924 & 6.818 \\
\hline
\end{tabular}

${ }^{\mathrm{a}} \mathrm{Bi} / \mathrm{Ti}$ was measured by ICP, ${ }^{\mathrm{b}} V_{\text {tot }}$ : the total pore volume, ${ }^{\mathrm{c}} \mathrm{D}$ : average pore diameter.

\section{Results and Discussions}

3.1. Textural Properties and Characterization Typical. Smallangle XRD patterns of calcined $\mathrm{Bi}-\mathrm{TiO}_{2} / \mathrm{SBA}-15(x)$ samples in the range of $0.5-5^{\circ}$ were shown in Figure 1(a). All samples exhibit well-resolved diffraction peak at $2 \vartheta=0.8-0.9^{\circ}$ corresponding to the (100) diffraction peak of the hexagonal features of the SBA-15, indicating that their ordered pore structure is maintained well. The position of the diffraction peak shifted to a higher angle indicating a small decrease of the pore size and unit cell. It is seen that SBA-15 has a good thermal stability. The diffraction intensity gradually decreased with increasing the calcination temperature.

Figure 1(b) shows the wide-angle XRD pattern of the Bi-TiO $2 / \mathrm{SBA}-15(x)$ calcined at different calcination temperatures. The XRD patterns of the samples evidenced that when the temperature is 400 and $550^{\circ} \mathrm{C}$, a typical broad diffraction peak centered at 29 of $25^{\circ}$, which is typical characteristic of amorphous silica. No clear characteristic peaks of crystalline $\mathrm{TiO}_{2}$ and $\mathrm{Bi}_{2} \mathrm{O}_{3}$ were observed in XRD patterns of sample, which indicated that the small nanoparticle sizes of $\mathrm{TiO}_{2}$ and $\mathrm{Bi}_{2} \mathrm{O}_{3}$ were successfully incorporated into the silica framework. However, sample calcined at $700^{\circ} \mathrm{C}$ shows the appearance of anatase phase. It is observed that, with increase of calcination temperature, $\mathrm{TiO}_{2}$ grain size increases. With further increase of calcination temperature to $850^{\circ} \mathrm{C}$, a new diffraction peak at $29=30^{\circ}$ was observed in the XRD pattern, which might be due to the formation a new phase of $\mathrm{Bi}_{4} \mathrm{Ti}_{3} \mathrm{O}_{12}$ at $850^{\circ} \mathrm{C}$. It is indicated that the new phase gradually dominates the composition of the samples. So it is feasible to control the ratio of the anatase phases by varying the calcination temperatures. In addition, no significant diffraction peak of $\mathrm{Bi}$ species was observed regardless of the calcination temperature because of the higher dispersion of $\mathrm{Bi}$ and the low content of $\mathrm{Bi}$.

The adsorption-desorption isotherms for $\mathrm{Bi}-\mathrm{TiO}_{2} / \mathrm{SBA}-15$ are shown in Figure 2(a). The samples exhibit isotherms of typical type IV with a $\mathrm{H} 2$ hysteresis loop due to the capillary condensation steps at relative pressure of $0.5<p / p_{0}<0.8$, which is characteristic of a mesopores material $[24,25]$. It can be clearly observed that the amount of $\mathrm{N}_{2}$ adsorption decreases upon $\mathrm{Bi}_{2} \mathrm{O}_{3}$ and $\mathrm{TiO}_{2}$ addition. Such a decrease of $\mathrm{N}_{2}$ adsorption for samples is reasonable, considering the formation of $\mathrm{Bi}_{2} \mathrm{O}_{3}$ and $\mathrm{TiO}_{2}$ nanoparticles inside the mesopores of SBA-15. When the calcination temperature increases to $850^{\circ} \mathrm{C}$, the isotherm changes to $\mathrm{H} 1$ hysteresis loop. The hysteresis loop in the isotherms is obviously shifted to the high relative pressure, indicating that pore sizes of the samples decrease with the calcination temperature.

The BET specific area and the pore size of $\mathrm{TiO}_{2} / \mathrm{SBA}$ 15 and $\mathrm{Bi}^{-\mathrm{TiO}_{2}} / \mathrm{SBA}-15(x)$ were summarized in Table 1. The specific surface area, pore size, and volume decrease 


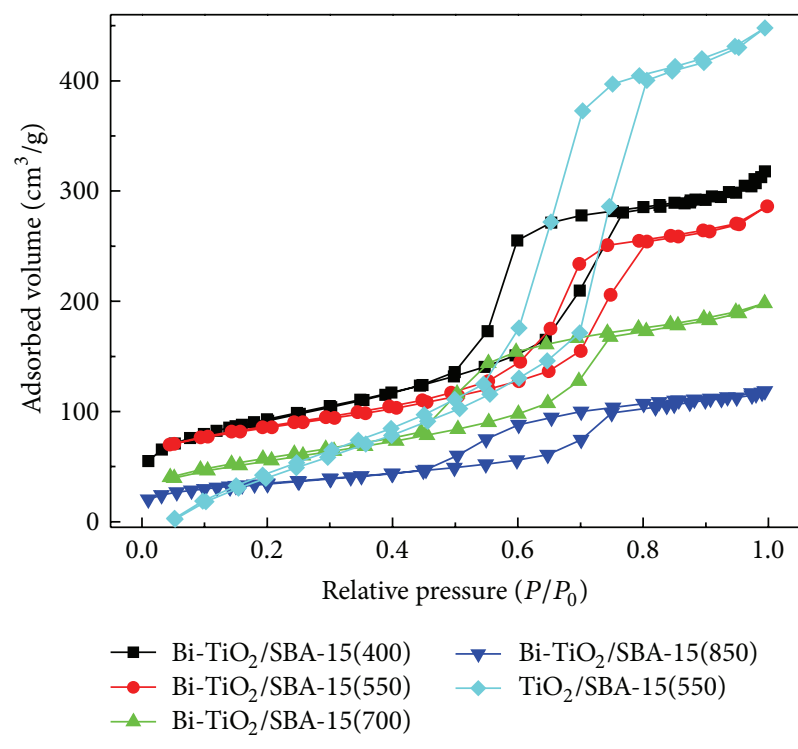

(a)

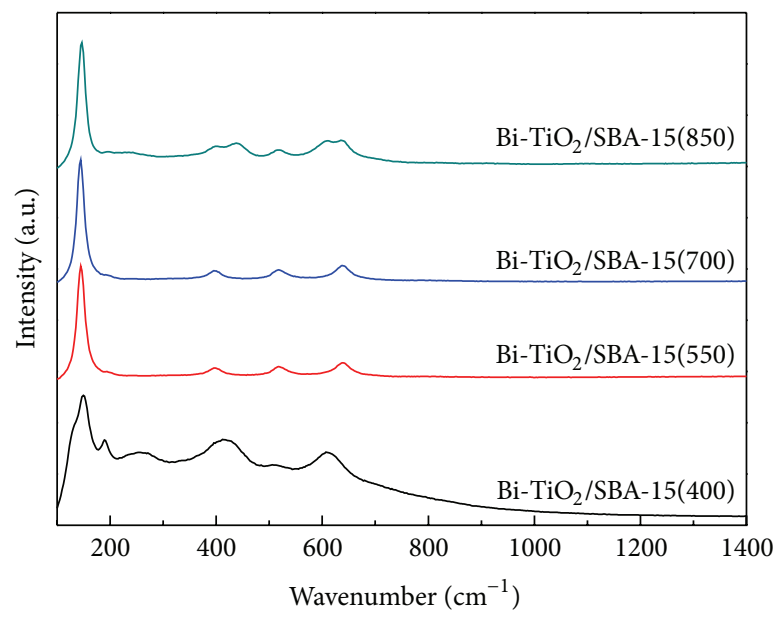

(b)

FIgURE 2: (a) $\mathrm{N}_{2}$ adsorption-desorption isotherms of $\mathrm{Bi}-\mathrm{TiO}_{2} / \mathrm{SBA}-15(x)$. (b) Raman spectra of $\mathrm{Bi}-\mathrm{TiO}_{2} / \mathrm{SBA}-15(x)$.

with the calcination temperature increasing. Based on the observations, with the calcination temperature increasing, total pore volume and BET surface area were decreased $16.0 \%$ and $5.9 \%$ at least, respectively. It is clear that the increasing calcination temperature leads to decrease pore volume, specific surface area, and the porosity of the samples. Meanwhile, the increasing calcination temperature helps to increase the $\mathrm{TiO}_{2}$ nanoparticles crystallization degree. We also noted that, when the temperature increased to $850^{\circ} \mathrm{C}$, there was a mutation of the specific surface area, which was attributed to the new phase, obstructing the pores of the SBA-15.

Raman spectroscopy further verified the $\mathrm{TiO}_{2}$ transformation for $\mathrm{Bi}^{-\mathrm{TiO}_{2}} / \mathrm{SBA}-15(x)$, as shown in Figure 2(b). The Raman bands appear at 147, 400,520, and $641 \mathrm{~cm}^{-1}$ and can be assigned to the $E_{g}, B_{1 g}, A_{1 g}$, and $B_{1 g}$ vibration modes of anatase $\mathrm{TiO}_{2}$ [26]. The results indicate that the doping of $\mathrm{Bi}$ has not influenced the anatase type of $\mathrm{TiO}_{2}$. A new peak appears at $200 \mathrm{~cm}^{-1}$ when the calcination temperature was $400^{\circ} \mathrm{C}$, which is attributed to the brookite phase. When the temperature is higher, the $\mathrm{TiO}_{2}$ in brookite phase has been full conversion to anatase with improving the crystalline. When the calcination temperature is up to $850^{\circ} \mathrm{C}, \mathrm{TiO}_{2}$ is still in anatase phase in the samples with partial conversion to a new phase of $\mathrm{Bi}_{4} \mathrm{Ti}_{3} \mathrm{O}_{12}$. It is indicated that the introduction of $\mathrm{Bi}$ can inhibit the transformation of $\mathrm{TiO}_{2}$ phase in the high temperature.

Figure 3 shows that it retains a regular hexagonal array of uniform channels characteristic of SBA- 15 with $\mathrm{Bi}$ and $\mathrm{TiO}_{2}$. It displays highly ordered hexagonal regularity mesopores, where nanoparticles are embedded in the pore walls with random orientation. When the calcination temperature is up to $850^{\circ} \mathrm{C}$, the nanocrystals structures do not change and slightly increased the nanoparticles size derived from XRD data. After the same treatment (up to $850^{\circ} \mathrm{C}$ ), the crystal domain size of $\mathrm{TiO}_{2}$ increased with partial conversion to
$\mathrm{Bi}_{4} \mathrm{Ti}_{3} \mathrm{O}_{12}$ and that of $\mathrm{Bi}_{2} \mathrm{O}_{3}$ crystals increased with partial conversion to monoclinic modification.

HRTEM image (Figure 3(e)) reveals that the materials were well crystallized, as evidenced by well-defined lattice fringes. The lattice fringes of $0.35 \mathrm{~nm}$ match the (101) plane of anatase $\mathrm{TiO}_{2}$, while that of $0.325 \mathrm{~nm}$ match the (120) plane of $\mathrm{Bi}_{2} \mathrm{O}_{3}$ nanoparticles, respectively. The HRTEM analysis confirmed that $\mathrm{Bi}_{2} \mathrm{O}_{3}$ and $\mathrm{TiO}_{2}$ coexisted in the resulting samples.

In order to analyze the chemical composition and purity of the prepared particles, the XPS survey spectrum of Bi$\mathrm{TiO}_{2} / \mathrm{SBA}-15$ is shown in Figure 4. Figure 4(a) shows that Bi$\mathrm{TiO}_{2} /$ SBA- 15 contains only $\mathrm{Ti}, \mathrm{O}, \mathrm{Bi}, \mathrm{Si}$, and $\mathrm{C}$ elements. The $\mathrm{C}$ element can be ascribed to the residual carbon from our characterization. The high-resolution XPS spectra of Bi4f are shown in Figure 4(b). The peaks of Bi $4 \mathrm{f} 7 / 2$ and Bi $4 \mathrm{f} 5 / 2$ are centered at 159.3 and $164.5 \mathrm{eV}$, which is in agreement with $\mathrm{Bi}_{2} \mathrm{O}_{3}$ values of other observations [27, 28]. After calcinations at higher temperature, these two peaks move a little to lower energies, hinting that bismuth element brings more effective positive charge and tends to convert to its stable oxidation state from +3 to 0 . The Bi species would segregate from the shallow surface and move onto the photocatalyst surface, and some $\mathrm{Bi}^{0}$ species are oxidized into $\mathrm{Bi}^{3+}$ species. This means that calcination may lead to more $\mathrm{Bi}_{2} \mathrm{O}_{3}$ species formed and to segregation on photocatalyst surface. A weak signal centred at $157.2 \mathrm{eV}$ indicated the existence of $\mathrm{Bi}^{0}[29]$.

The XPS spectra of $\mathrm{O} 1 \mathrm{~s}$ are shown in Figure 4(c). The O 1s peak is broad and complicated due to the nonequivalence of oxygen ions. The peak shape suggests that it is composed of multiple peaks that arise due to the overlapping contributions of oxide ions. The strong peak at $529.8 \mathrm{eV}$ is ascribed to Ti$\mathrm{O}$ bond in $\mathrm{TiO}_{2}$, the peak at $531.4 \mathrm{eV}$, which is assigned to the oxygen attached to bismuth ( $\mathrm{Bi}-\mathrm{O}$ bond), and 


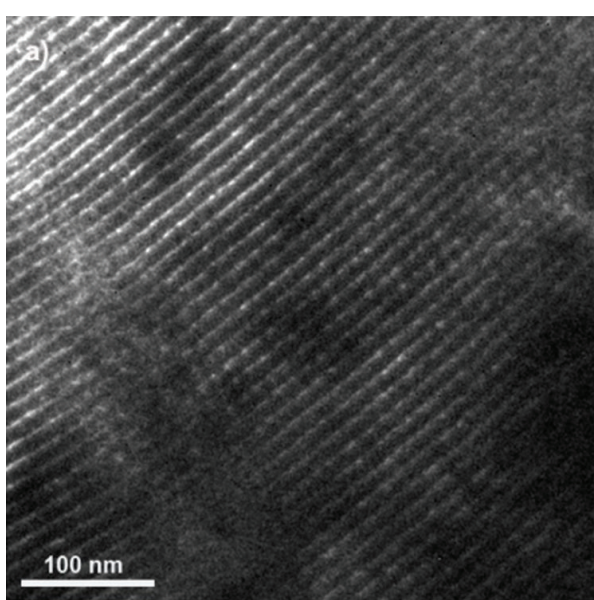

(a)

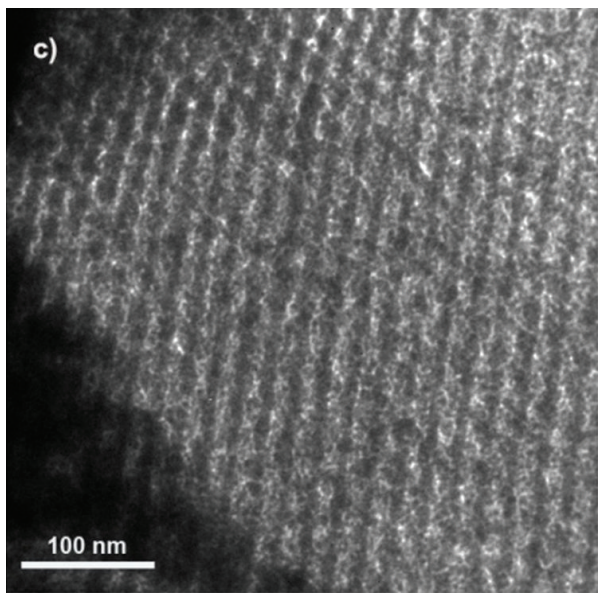

(c)

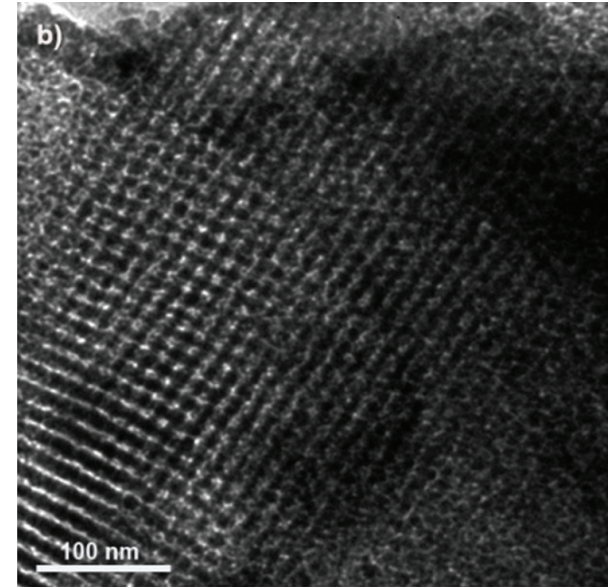

(b)

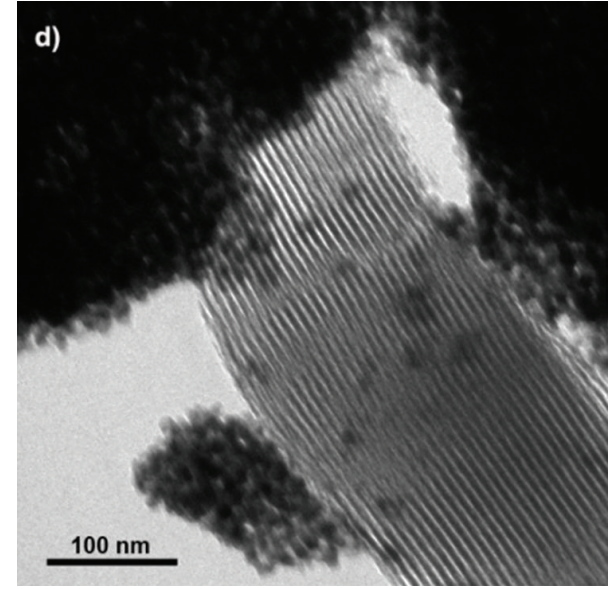

(d)

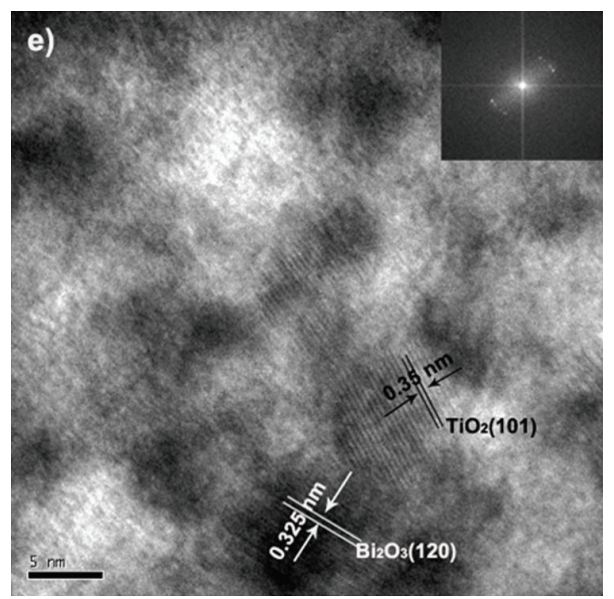

(e)

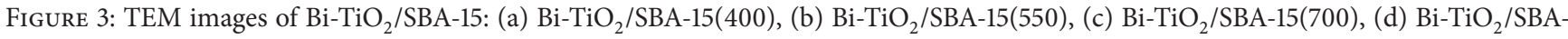
15(850), and (e) HRTEM image of $\mathrm{Bi}^{-} \mathrm{TiO}_{2} / \mathrm{SBA}-15(550)$ (inset is the corresponding FFT pattern).

the shoulder at $533.6 \mathrm{eV}$ is attributed to the $\mathrm{OH}^{-}$group absorbed on the surface. The Ti $2 \mathrm{p}$ of $\mathrm{Bi}-\mathrm{TiO}_{2} / \mathrm{SBA}-15$ is shown in Figure 4(d). The peaks of Ti2p3/2 and Ti2p1/2 were centered at 458.2 and $464.7 \mathrm{eV}$, which showed that the main valence of $\mathrm{Ti}$ in the prepared catalysts is +4 and $\mathrm{Ti}^{4+}$ is in tetrahedral coordination with oxygen in the catalysts. Meanwhile, there was no significant influence on the spectra in either Ti $2 \mathrm{p}$ or O 1 s in the presence of $\mathrm{Bi}_{2} \mathrm{O}_{3}$. 


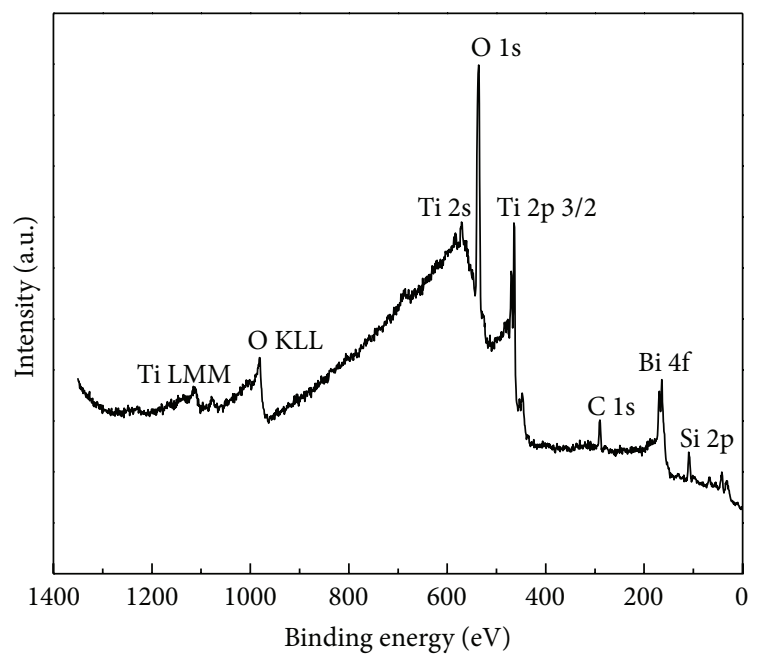

(a)

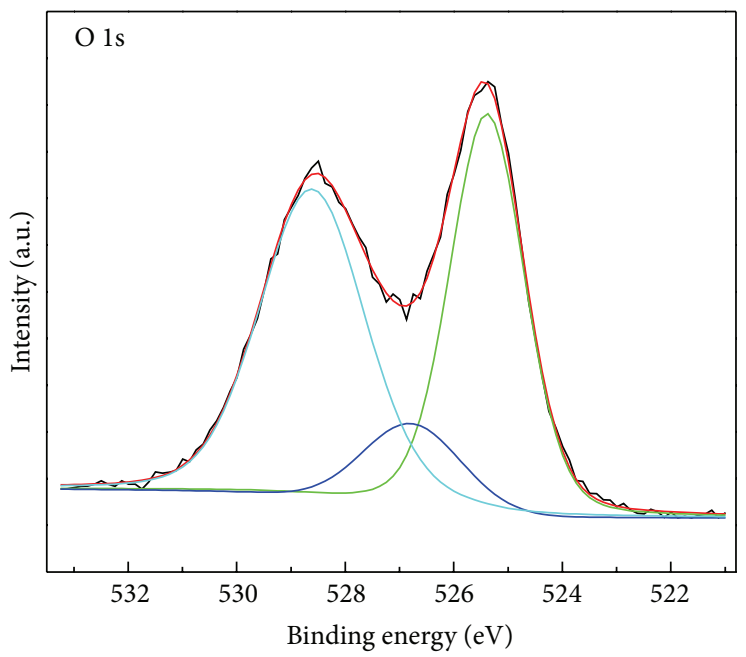

(c)

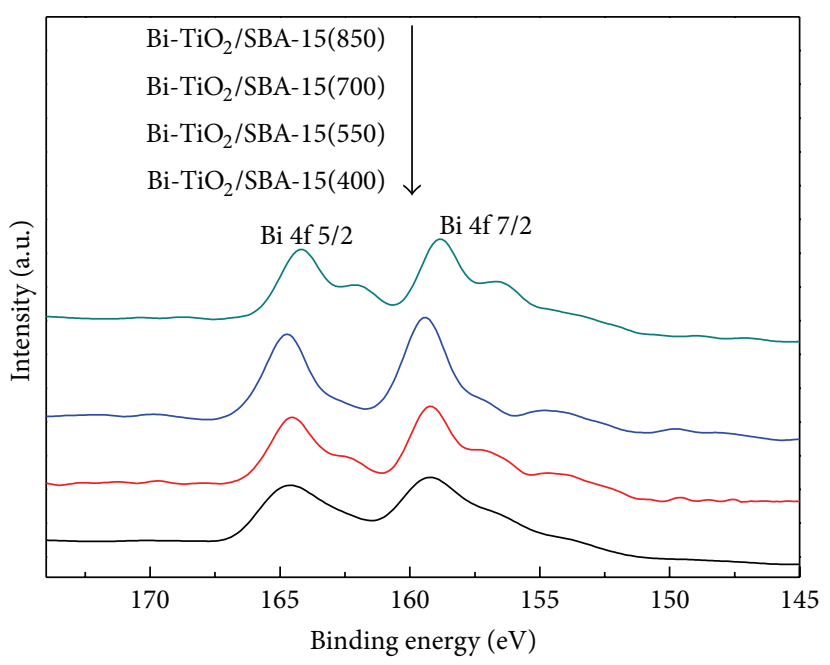

(b)

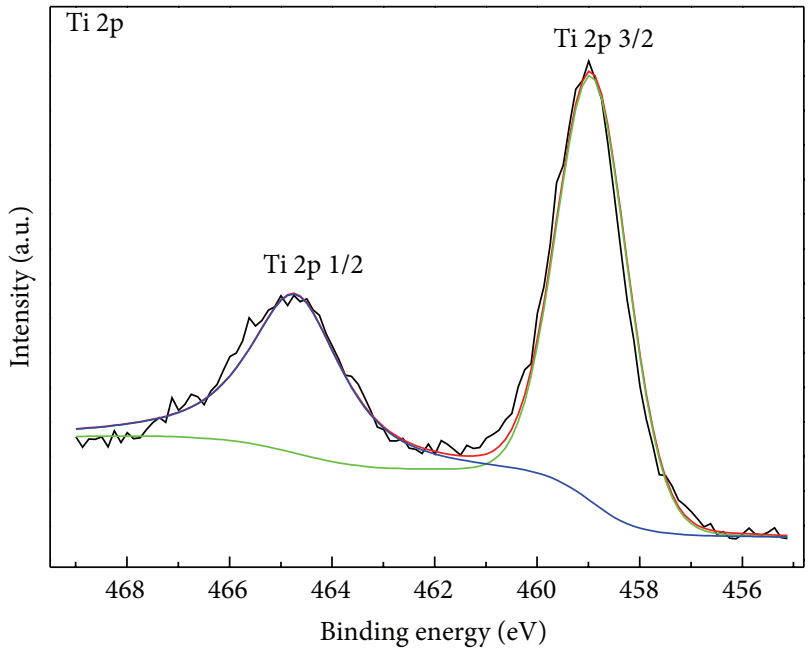

(d)

Figure 4: XPS survey spectrum of $\mathrm{Bi}_{-}-\mathrm{TiO}_{2} / \mathrm{SBA}-15$ (a), the high-resolution XPS spectra of $\mathrm{Bi} 4 \mathrm{f}$ region (b), O 1s (c), and Ti 2p (d).

The UV-Vis absorption spectra of the $\mathrm{Bi}-\mathrm{TiO}_{2} / \mathrm{SBA}-15$ were presented in Figure 5(a). There a red shift for Bi$\mathrm{TiO}_{2} /$ SBA-15 in the visible region. The results show that the doping of Bi can increase the absorbance of visible light and extend the absorption edge to longer wavelengths. It can be seen that the $\mathrm{Bi}-\mathrm{TiO}_{2} / \mathrm{SBA}-15$ calcined at $400-700^{\circ} \mathrm{C}$ displayed similar absorbance for visible lights, suggesting that, in the composite, $\mathrm{Bi}_{2} \mathrm{O}_{3}$ mainly resulted in the spectral response in the visible region. However, with the increase of calcination temperature to $850^{\circ} \mathrm{C}$, the $\mathrm{Bi}-\mathrm{TiO}_{2} / \mathrm{SBA}-15$ showed an obviously stronger absorption in the visible light region than that of calcined at other temperatures, which might be due to the formation of a new phase of $\mathrm{Bi}_{4} \mathrm{Ti}_{3} \mathrm{O}_{12}$ at $850^{\circ} \mathrm{C}$. Moreover, the plot of $(\alpha h \nu)^{1 / 2}$ versus the energy of light afforded band gap energy of $2.81 \mathrm{eV}$ for $\mathrm{Bi}^{-} \mathrm{TiO}_{2} / \mathrm{SBA}-15$ (see the inset in Figure 5(a)), which could be easily induced photoelectrons and holes by visible lights.

PL emission spectra have been used to investigate the efficiency of charge carrier trapping, immigration, transfer and to understand the fate of electron-hole pairs in semiconductor particles [30]. Figure 5(b) showed the PL spectra of $\mathrm{TiO}_{2}$ and $\mathrm{Bi}-\mathrm{TiO}_{2} / \mathrm{SBA}-15$ in the range of $400-$ $525 \mathrm{~nm}$. The PL intensity of the samples decreases as follows: $\mathrm{TiO}_{2}>\mathrm{Bi}^{-\mathrm{TiO}_{2}} / \mathrm{SBA}-15(400)>\mathrm{Bi}^{-} \mathrm{TiO}_{2} / \mathrm{SBA}-15(700)>\mathrm{Bi}-$ $\mathrm{TiO}_{2} / \mathrm{SBA}-15(850)>\mathrm{Bi}^{-\mathrm{TiO}_{2}} / \mathrm{SBA}-15(550)$. It indicated that, when increasing the calcination temperature, the decrease in trap states on samples surface may slow the recombination process of photogenerated electrons and holes in $\mathrm{TiO}_{2}$, which benefit the photocatalytic reaction.

3.2. The Photocatalytic Activity of $\mathrm{Bi}-\mathrm{TiO}_{2} / \mathrm{SBA}-15$. The UVVis absorption spectra clearly reveal that the visible light absorption of $\mathrm{Bi}^{-} \mathrm{TiO}_{2} / \mathrm{SBA}-15$ is higher than that of $\mathrm{TiO}_{2}$. Therefore, it is reasonable to expect higher photocatalytic activity when the $\mathrm{Bi}$ species and $\mathrm{TiO}_{2}$ deposited on the SBA-15 mesostructure. We evaluated the $\mathrm{Bi}-\mathrm{TiO}_{2} / \mathrm{SBA}-15(x)$ samples for degradation of $\mathrm{RhB}$ under visible light irradiation and compared the catalytic efficiency of $\mathrm{Bi}-\mathrm{TiO}_{2} / \mathrm{SBA}-15(x)$ with 

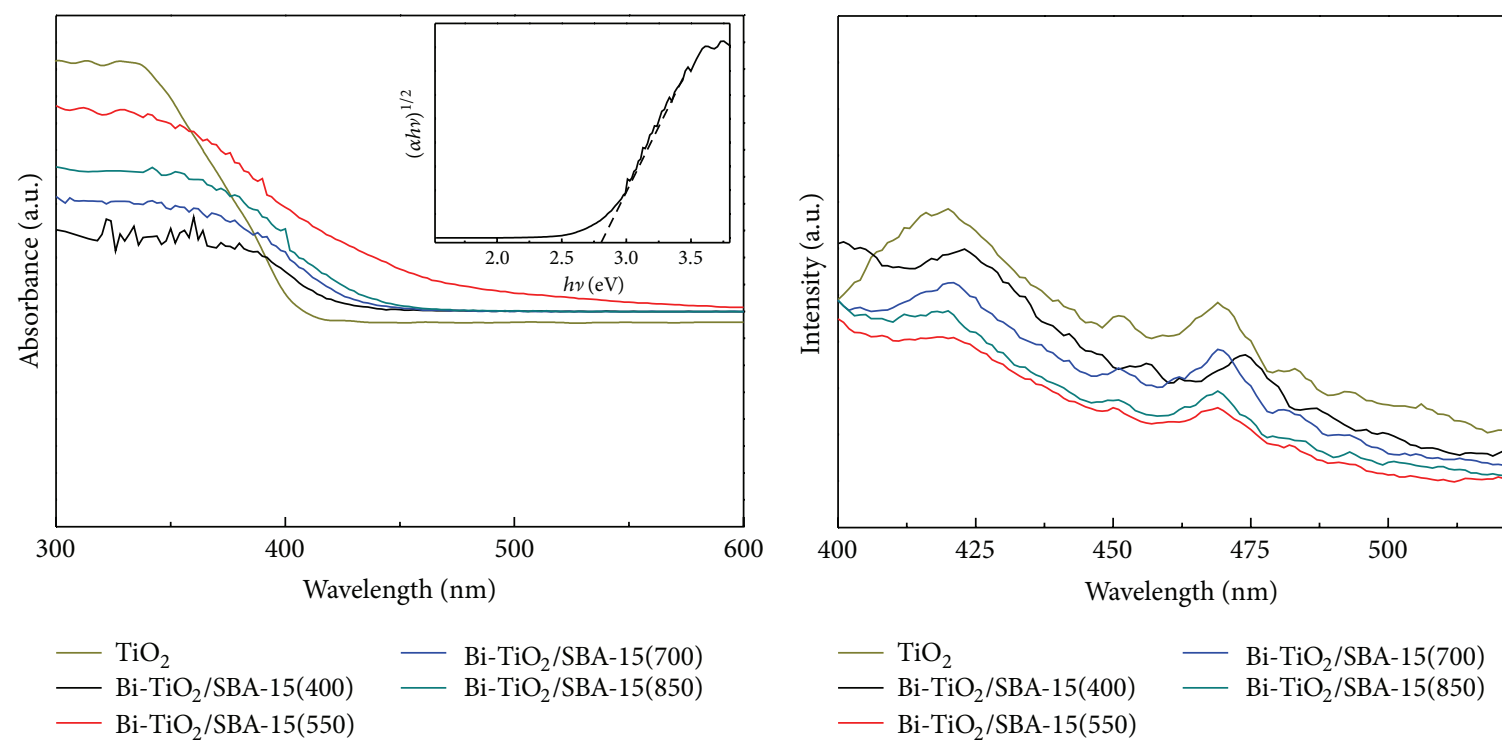

$\begin{array}{ll}-\mathrm{TiO}_{2} & -\mathrm{Bi}_{-\mathrm{TiO}_{2} / \mathrm{SBA}-15(700)} \\ -\mathrm{Bi}_{\mathrm{TiO}} / \mathrm{SBA}-15(400) & \mathrm{Bi}-\mathrm{TiO}_{2} / \mathrm{SBA}-15(850) \\ -\mathrm{Bi}_{2}-\mathrm{TiO}_{2} / \mathrm{SBA}-15(550) & \end{array}$

(a)

(b)

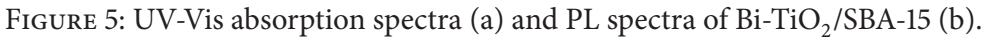

that of $\mathrm{TiO}_{2}$. The photoactivities for $\mathrm{RhB}$ in dark in the presence of the photocatalyst under visible light irradiation in the absence of the photocatalyst are evaluated. It is found that there was no degradation for the $\mathrm{RhB}$ in the dark and in the presence of the photocatalyst. There is no degradation observed for $\mathrm{RhB}$ when the solution is placed under visible light radiation without the addition of photocatalysts.

Figure 6(a) displayed the effect of the calcination temperature on the photocatalytic activity. The activities decrease

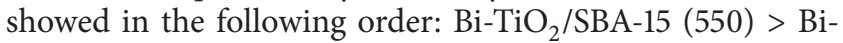
$\mathrm{TiO}_{2} / \mathrm{SBA}-15(850)>\mathrm{Bi}-\mathrm{TiO}_{2} / \mathrm{SBA}-15(700)>\mathrm{Bi}^{-\mathrm{TiO}_{2}} / \mathrm{SBA}-$ $15(400)>\mathrm{Bi}_{2} \mathrm{O}_{3} /$ SBA-15 $>\mathrm{TiO}_{2} /$ SBA-15(550) $>\mathrm{Bi}_{2} \mathrm{O}_{3}>\mathrm{TiO}_{2}$.

It is well known that pure $\mathrm{TiO}_{2}$ and $\mathrm{TiO}_{2} / \mathrm{SBA}-15$ have no photocatalytic activity under visible light irradiation. However, in Figure 6(a), the experiment results show a little decomposition ability of $\mathrm{RhB}$, which is due to the small size of $\mathrm{TiO}_{2}$ nanoparticles improving the photocatalytic activity. The degradation efficiency by $\mathrm{Bi}_{2} \mathrm{O}_{3} / \mathrm{SBA}-15$ and $\mathrm{Bi}_{2} \mathrm{O}_{3}$ is also low.

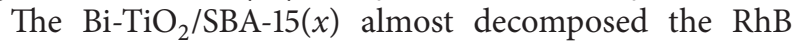
solution within $90 \mathrm{~min}$, compared to the $\mathrm{TiO}_{2}$ sample, which implies that the doped $\mathrm{Bi}$ is essential as a cocatalyst for the efficient degradation. That is to say, the Bi doping on $\mathrm{TiO}_{2} /$ SBA-15 is accorded to the higher photodegradation, which resulted from the formation of Bi species enhancing the electron and hole separation by capturing the photoinduced charges efficiently. There are two reasons for the superior photocatalytic performance. Firstly, valence band (VB) composed of hybridized $\mathrm{Bi} 6 \mathrm{~s}$, Ti 3d, and O 2p orbitals has a strong oxidizing ability and can effectively degrade organic pollutants. And the hybridization of the $\mathrm{Bi} 6 \mathrm{~s}$, $\mathrm{Ti} 3 \mathrm{~d}$, and $\mathrm{O} 2 \mathrm{p}$ levels makes the VB largely dispersed, which favors the mobility of photoholes in the VB and is beneficial for the oxidation reaction. Secondly, the assembled $\mathrm{Bi}_{2} \mathrm{O}_{3}$ increases the mobility of the photogenerated carriers, and good crystallization may lead to the enhancement of photocatalytic activity for the decomposition of the organic compounds. It is allowing more opportunities for electrons to participate in the reduction reaction to form active oxygen species. The transfer of the photoexcited electrons from the surface of $\mathrm{Bi}_{2} \mathrm{O}_{3}$ to $\mathrm{TiO}_{2}$ occurs due to the small $\mathrm{Bi}_{2} \mathrm{O}_{3}$ band gap and its higher conduction band potential compared to that of $\mathrm{TiO}_{2}$.

It is known that photodegradation kinetics follow Langmuir-Hinshelwood kinetics model [31]. The reaction can be represented as follows (1):

$$
\ln \frac{C_{0}}{C}=k_{\text {app }} t,
$$

where $k_{\text {app }}$ is the apparent first-order reaction constant and $C_{0}$ is the initial concentration of the $\mathrm{RhB}$ solution. A kinetic linear simulation curve of $\mathrm{RhB}$ photocatalytic degradation using $\mathrm{Bi}_{-}-\mathrm{TiO}_{2} / \mathrm{SBA}-15(x)$ is shown in Figure 6(b). The fact that the curve showed good linearity indicating that the photocatalytic degradation of $\mathrm{RhB}$ using $\mathrm{Bi}^{-\mathrm{TiO}_{2}} / \mathrm{SBA}-15(x)$ as catalyst fits well with the first-order reaction kinetics. The rate constant of $\mathrm{Bi}^{-}-\mathrm{TiO}_{2} / \mathrm{SBA}-15(x)$ for $\mathrm{RhB}$ photodegradation is

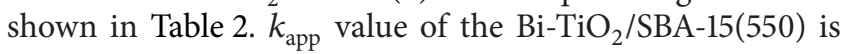
$0.0212 \mathrm{~min}^{-1}$, which is higher than that of $\mathrm{TiO}_{2}$ and other samples of $\mathrm{Bi}^{-} \mathrm{TiO}_{2} / \mathrm{SBA}-15$. It suggested that $k_{\text {app }}$ improved by Bi doping. It is widely accepted that the high calcination temperature usually results in smaller specific surface area and particle size, as illustrated in Table 1. The calcination temperature strongly influenced the activity of the samples. Though the sample calcined at $400^{\circ} \mathrm{C}$ has the largest BET surface area and particle size, its crystalline is worse than that of the calcined at higher temperature, leading to lower photoactivity. Meanwhile, the effect of the photocatalytic activity is decreased when the calcination temperature is up to $700-850^{\circ} \mathrm{C}$. It can be explained that the high calcination 


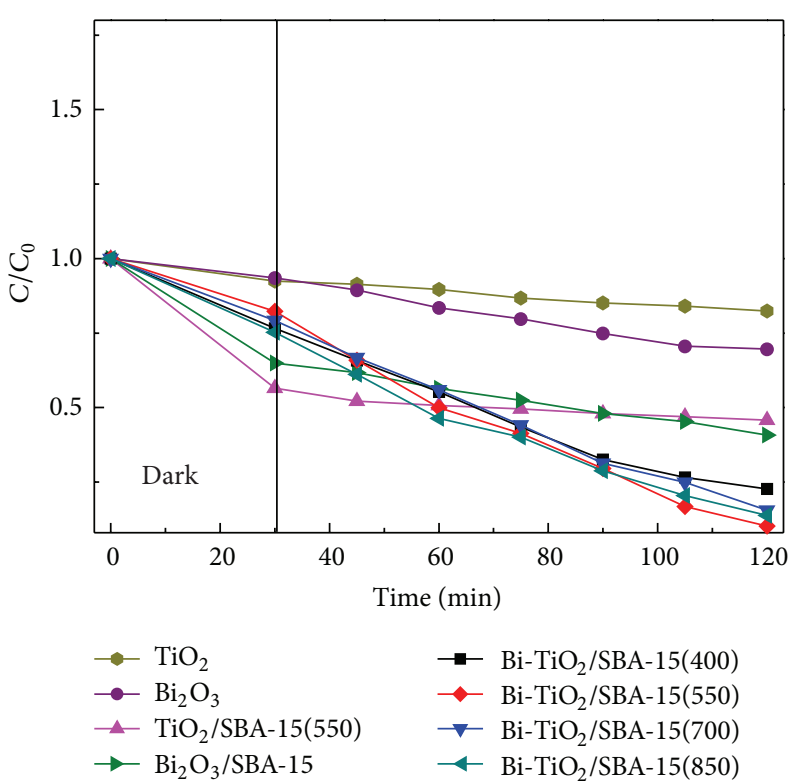

(a)

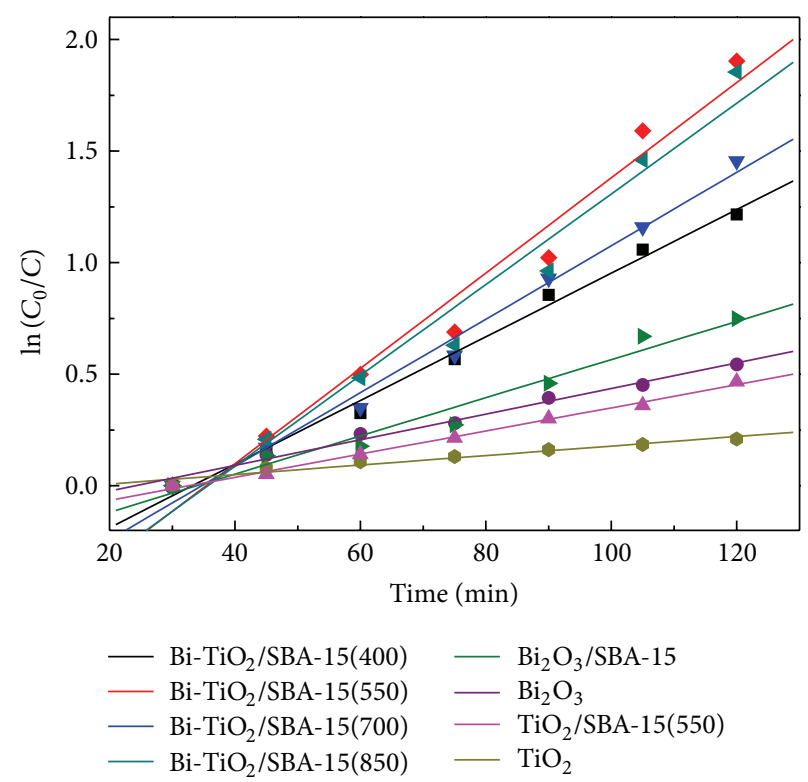

(b)

Figure 6: Photocatalytic activity (a) and kinetic linear simulation curve (b) of photocatalytic degradation by $\mathrm{Bi}^{-\mathrm{TiO}} \mathrm{O}_{2} / \mathrm{SBA}-15(x)$ under visible light.

TABLE 2: The rate constant of $\mathrm{Bi}_{-} \mathrm{TiO}_{2} / \mathrm{SBA}-15(x)$ for $\mathrm{RhB}$ photodegradation.

\begin{tabular}{|c|c|}
\hline Samples & $k_{\mathrm{app}}\left(\min ^{-1}\right)$ \\
\hline $\mathrm{Bi}^{-\mathrm{TiO}_{2} / \mathrm{SBA}-15(400)}$ & 0.0135 \\
\hline $\mathrm{Bi}-\mathrm{TiO}_{2} / \mathrm{SBA}-15(550)$ & 0.0212 \\
\hline $\mathrm{Bi}-\mathrm{TiO}_{2} / \mathrm{SBA}-15(700)$ & 0.0162 \\
\hline $\mathrm{Bi}-\mathrm{TiO}_{2} / \mathrm{SBA}-15(850)$ & 0.0206 \\
\hline $\mathrm{Bi}_{2} \mathrm{O}_{3} / \mathrm{SBA}-15$ & 0.00818 \\
\hline $\mathrm{TiO}_{2} / \mathrm{SBA}-15(550)$ & 0.00553 \\
\hline $\mathrm{Bi}_{2} \mathrm{O}_{3}$ & 0.00755 \\
\hline $\mathrm{TiO}_{2}$ & 0.00540 \\
\hline
\end{tabular}

temperature destructed pore structure and caused loss in surface area to some extent, reducing the oxygen vacancies. The samples at $850^{\circ} \mathrm{C}$ show better photocatalytic activity than samples at $700^{\circ} \mathrm{C}$, which might be due to the formation of a new phase of $\mathrm{Bi}_{4} \mathrm{Ti}_{3} \mathrm{O}_{12}$ having higher photocatalytic activity. The sample calcined at $550^{\circ} \mathrm{C}$ shows the highest photocatalytic activity in the decomposition of RhB under visible light. Furthermore, the doping of Bi could effectively limit the phase transformation, preventing the overgrowth of crystallites and enhancing the visible light absorption in comparison with $\mathrm{TiO}_{2}$ and $\mathrm{TiO}_{2} / \mathrm{SBA}-15$.

In addition, the $\mathrm{Bi}-\mathrm{TiO}_{2} / \mathrm{SBA}-15$ obtained at $550^{\circ} \mathrm{C}$ presents the highest photocatalytic activity. However, as an excellent catalyst, it should not only show higher activity but also present stability in recycle process. As shown in Figure $7, \mathrm{Bi}-\mathrm{TiO}_{2} / \mathrm{SBA}-15$ can preserve most of its catalytic activity after six cycles and this confirms that the as-prepared $\mathrm{Bi}-\mathrm{TiO}_{2} / \mathrm{SBA}-15$ is stable under irradiation for photocatalytic decomposition of organic pollutants.

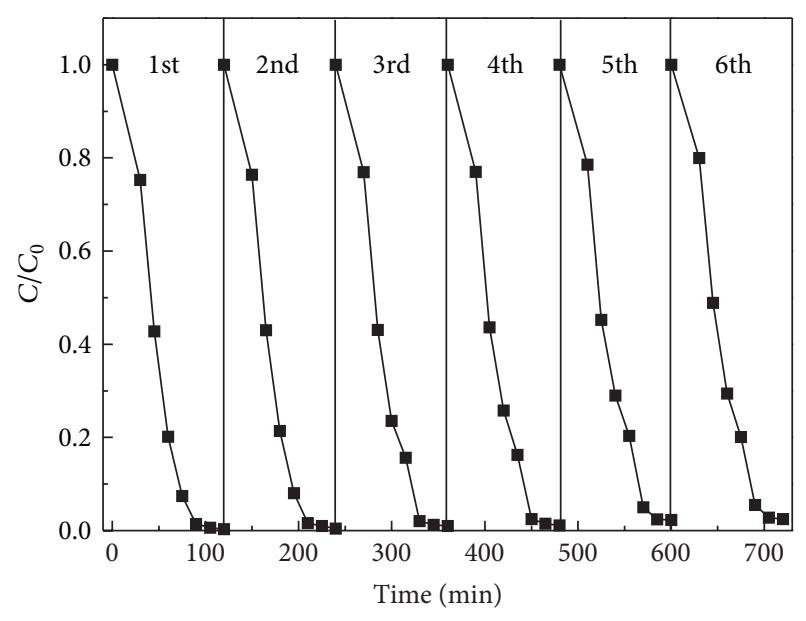

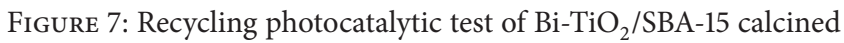
at $550^{\circ} \mathrm{C}$.

\section{Conclusions}

In conclusion, we have fabricated a visible photocatalyst Bi-TiO $2 /$ SBA-15 material. The photocatalytic activity of the prepared photocatalysts was investigated by the photodegradation of RhB. A combination of XRD, XPS, Raman, nitrogen adsorption-desorption isotherm measurement, TEM, and UV-Vis absorption spectra has been used to characterize the $\mathrm{Bi}-\mathrm{TiO}_{2} / \mathrm{SBA}-15$ material. The experiment results indicated that the Bi doping could enhance the photocatalytic activities than $\mathrm{TiO}_{2}$. The calcination temperature strongly influenced the activity of the samples. The sample calcined at $550^{\circ} \mathrm{C}$ shows the highest photocatalytic activity in the decomposition of $\mathrm{RhB}$ under visible light. This work provides a new 
pathway to design and fabricate novel photoactive materials for practical application in environmental cleaning.

\section{Conflict of Interests}

The authors declare that they do not have any commercial or associative interests that represents a conflict of interest directly or indirectly in connection with our work.

\section{Acknowledgments}

The authors are grateful for the financial support from the National Natural Science Foundation of China (no. 50978212), the State Key Program of Shaanxi Province Natural Science Foundation Project (no. 2012JZ7003), the Shaanxi Province Science and Technology and Innovation Project Foundation (no. 2011KTDZ01-05-05), and the Science Foundation from Education Department of Shaanxi Provincial Government (no. 2013JK0885 and no. 2013JK0650).

\section{References}

[1] A. Fujishima and K. Honda, "Electrochemical photolysis of water at a semiconductor electrode," Nature, vol. 238, no. 5358, pp. 37-38, 1972.

[2] J. Zhang, Z. Xiong, and X. S. Zhao, "Graphene-metal-oxide composites for the degradation of dyes under visible light irradiation," Journal of Materials Chemistry, vol. 21, no. 11, pp. 3634-3640, 2011.

[3] Y. Wang, R. Shi, J. Lin, and Y. Zhu, "Enhancement of photocurrent and photocatalytic activity of $\mathrm{ZnO}$ hybridized with graphite-like $\mathrm{C}_{3} \mathrm{~N}_{4}$," Energy and Environmental Science, vol. 4, no. 8, pp. 2922-2929, 2011.

[4] Q. Y. Li, T. Kako, and J. H. Ye, " $\mathrm{WO}_{3}$ modified titanate network film: highly efficient photo-mineralization of 2-propanol under visible light irradiation," Chemical Communications, vol. 46, no. 29, pp. 5352-5354, 2010.

[5] R. Li, W. Chen, H. Kobayashi, and C. Ma, "Platinumnanoparticle-loaded bismuth oxide: an efficient plasmonic photocatalyst active under visible light," Green Chemistry, vol. 12, no. 2, pp. 212-215, 2010.

[6] J. Wang, Q. Cai, H. Li, Y. Cui, and H. Wang, "A review on $\mathrm{TiO}_{2}$ nanotube film photocatalysts prepared by liquid-phase deposition," International Journal of Photoenergy, vol. 2012, Article ID 702940, 11 pages, 2012.

[7] H. Chen, J. Li, Q. Chen, D. Li, and B. Zhou, "Photoelectrocatalytic performance of benzoic acid on $\mathrm{TiO}_{2}$ nanotube array electrodes," International Journal of Photoenergy, vol. 2013, Article ID 567426, 7 pages, 2013.

[8] Y. Wang, Y. Wang, Y. Meng et al., "A highly efficient visible-lightactivated photocatalyst based on bismuth- and sulfur-codoped $\mathrm{TiO}_{2}$," Journal of Physical Chemistry C, vol. 112, no. 17, pp. 66206626, 2008.

[9] L. Q. Jing, J. Wang, Y. C. Qu, and Y. B. Luan, "Effects of surfacemodification with $\mathrm{Bi}_{2} \mathrm{O}_{3}$ on the thermal stability and photoinduced charge property of nanocrystalline anatase $\mathrm{TiO}_{2}$ and its enhanced photocatalytic activity," Applied Surface Science, vol. 256, no. 3, pp. 657-663, 2009.
[10] Y. Q. Wu, G. X. Lu, and S. B. Li, “The doping effect of Bi on $\mathrm{TiO}_{2}$ for photocatalytic hydrogen generation and photodecolorization of rhodamine B," Journal of Physical Chemistry C, vol. 113, no. 22, pp. 9950-9955, 2009.

[11] J. Hou, C. Yang, Z. Wang, S. Jiao, and $\mathrm{H}$. $\mathrm{Zhu,}{ }^{\mathrm{B}} \mathrm{Bi}_{2} \mathrm{O}_{3}$ quantum dots decorated anatase $\mathrm{TiO}_{2}$ nanocrystals with exposed (001) facets on graphene sheets for enhanced visible-light photocatalytic performance," Applied Catalysis B, vol. 129, pp. 333-341, 2013.

[12] D. Di Camillo, F. Ruggieri, S. Santucci, and L. Lozzi, "Ndoped $\mathrm{TiO}_{2}$ nanofibers deposited by electrospinning," Journal of Physical Chemistry C, vol. 116, pp. 18427-18431, 2012.

[13] K. Su, Z. Ai, and L. Zhang, "Efficient visible light-driven photocatalytic degradation of pentachlorophenol with $\mathrm{Bi}_{2} \mathrm{O}_{3} / \mathrm{TiO}_{2}$ xBx," Journal of Physical Chemistry C, vol. 116, pp. 17118-17123, 2012.

[14] H. Y. Li, D. J. Wang, P. Wang, H. Fan, and T. Xie, "Synthesis and studies of the visible-light photocatalytic properties of nearmonodisperse $\mathrm{Bi}$-doped $\mathrm{TiO}_{2}$ nanospheres," Chemistry, vol. 15, no. 45, pp. 12521-12527, 2009.

[15] S. Shamaila, A. K. L. Sajjad, F. Chen, and J. L. Zhang, "Study on highly visible light active $\mathrm{Bi}_{2} \mathrm{O}_{3}$ loaded ordered mesoporous titania," Applied Catalysis B, vol. 94, no. 3-4, pp. 272-280, 2010.

[16] S. Rengaraj, X. Z. Li, P. A. Tanner, Z. F. Pan, and G. K. H. Pang, "Photocatalytic degradation of methylparathion - an endocrine disruptor by $\mathrm{Bi}^{3+}$-doped $\mathrm{TiO}_{2}$," Journal of Molecular Catalysis A, vol. 247, no. 1-2, pp. 36-43, 2006.

[17] W. J. J. Stevens, K. Lebeau, M. Mertens, G. Van Tendeloo, P. Cool, and E. F. Vansant, "Investigation of the morphology of the mesoporous SBA-16 and SBA-15 materials," Journal of Physical Chemistry B, vol. 110, no. 18, pp. 9183-9187, 2006.

[18] C.-C. Yang, J. Vernimmen, V. Meynen, P. Cool, and G. Mul, "Mechanistic study of hydrocarbon formation in photocatalytic $\mathrm{CO}_{2}$ reduction over Ti-SBA-15," Journal of Catalysis, vol. 284, no. 1, pp. 1-8, 2011.

[19] S. C. Zhang, D. Jiang, T. Tang et al., " $\mathrm{TiO}_{2} / \mathrm{SBA}-15$ photocatalysts synthesized through the surface acidolysis of $\mathrm{Ti}(\mathrm{OnBu})_{4}$ on carboxyl-modified SBA-15," Catalysis Today, vol. 158, no. 3-4, pp. 329-335, 2010.

[20] V. Tajer-Kajinebaf, H. Sarpoolaky, and T. Mohammadi, "Synthesis of nanostructured anatase mesoporous membranes with photocatalytic and separation capabilities for water ultrafiltration process," International Journal of Photoenergy, vol. 2013, Article ID 509023, 11 pages, 2013.

[21] D. Zhao, J. Feng, Q. Huo et al., "Triblock copolymer syntheses of mesoporous silica with periodic 50 to 300 angstrom pores," Science, vol. 279, no. 5350, pp. 548-552, 1998.

[22] D. Zhao, Q. Huo, J. Feng, G. H. Fredrickson, and G. D. Stucky, "Nonionic triblock and star diblock copolymer and oligomeric sufactant syntheses of highly ordered, hydrothermally stable, mesoporous silica structures," Journal of the American Chemical Society, vol. 120, no. 24, pp. 6024-6036, 1998.

[23] J. Ma, J. Chu, L. S. Qiang, and J. Xue, "Synthesis and structural characterization of novel visible photocatalyst $\mathrm{Bi}-\mathrm{TiO}_{2} / \mathrm{SBA}-15$ and its photocatalytic performance," RSC Advances, vol. 2, pp. 3753-3758, 2012.

[24] S. Y. Chai, Y. J. Kim, M. H. Jung, A. K. Chakraborty, D. Jung, and W. I. Lee, "Heterojunctioned $\mathrm{BiOCl} / \mathrm{Bi}_{2} \mathrm{O}_{3}$, a new visible light photocatalyst," Journal of Catalysis, vol. 262, no. 1, pp. 144-149, 2009.

[25] Q. S. Huo, R. Leon, P. M. Petroff, and G. D. Stucky, "Mesostructure design with gemini surfactants: supercage formation in 
a three-dimensional hexagonal array," Science, vol. 268, no. 5215, pp. 1324-1327, 1995.

[26] Y. J. Acosta-Silva, R. Nava, V. Hernández-Morales, S. A. MacíasSánchez, M. L. Gómez-Herrera, and B. Pawelec, "Methylene blue photodegradation over titania-decorated SBA-15," Applied Catalysis B, vol. 110, pp. 108-117, 2011.

[27] S. Perathoner, P. Lanzafame, R. Passalacqua, G. Centi, R. Schlögl, and D. S. Su, "Use of mesoporous SBA-15 for nanostructuring titania for photocatalytic applications," Microporous and Mesoporous Materials, vol. 90, no. 1-3, pp. 347-361, 2006.

[28] J. J. Xu, Y. H. Ao, D. G. Fu, and C. Yuan, "Synthesis of $\mathrm{Bi}_{2} \mathrm{O}_{3}-\mathrm{TiO}_{2}$ composite film with high-photocatalytic activity under sunlight irradiation," Applied Surface Science, vol. 255, no. 5, pp. 23652369, 2008.

[29] M.-W. Chu, M. Ganne, M. T. Caldes, and L. Brohan, "X-ray photoelectron spectroscopy and high resolution electron microscopy studies of Aurivillius compounds: $\mathrm{Bi}_{4-x} \mathrm{La}_{X} \mathrm{Ti}_{3} \mathrm{O}_{12}(x=0$, 0.5, 0.75, 1.0, 1.5, and 2.0)," Journal of Applied Physics, vol. 91, no. 5, pp. 3178-3187, 2002.

[30] Y. Z. Li and S.-J. Kim, "Synthesis and characterization of nano titania particles embedded in mesoporous silica with both high photocatalytic activity and adsorption capability," Journal of Physical Chemistry B, vol. 109, no. 25, pp. 12309-12315, 2005.

[31] S. Zheng, Y. Cai, and K. E. O'Shea, “ $\mathrm{TiO}_{2}$ photocatalytic degradation of phenylarsonic acid," Journal of Photochemistry and Photobiology A, vol. 210, no. 1, pp. 61-68, 2010. 

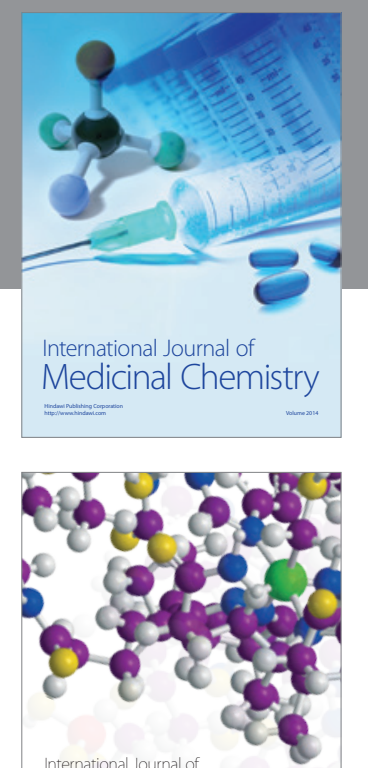

\section{Carbohydrate} Chemistry

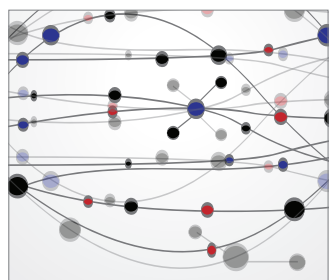

The Scientific World Journal
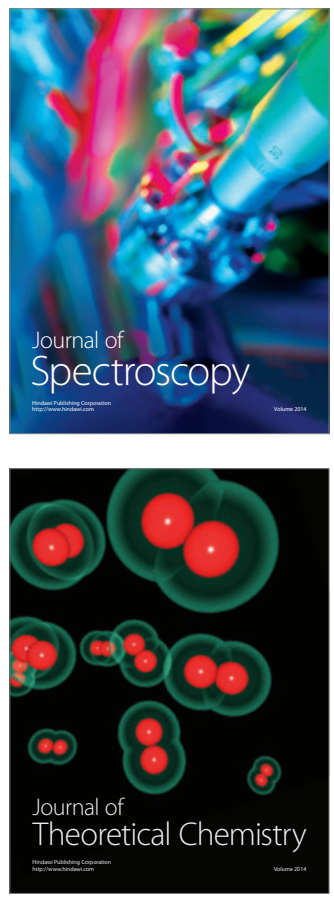
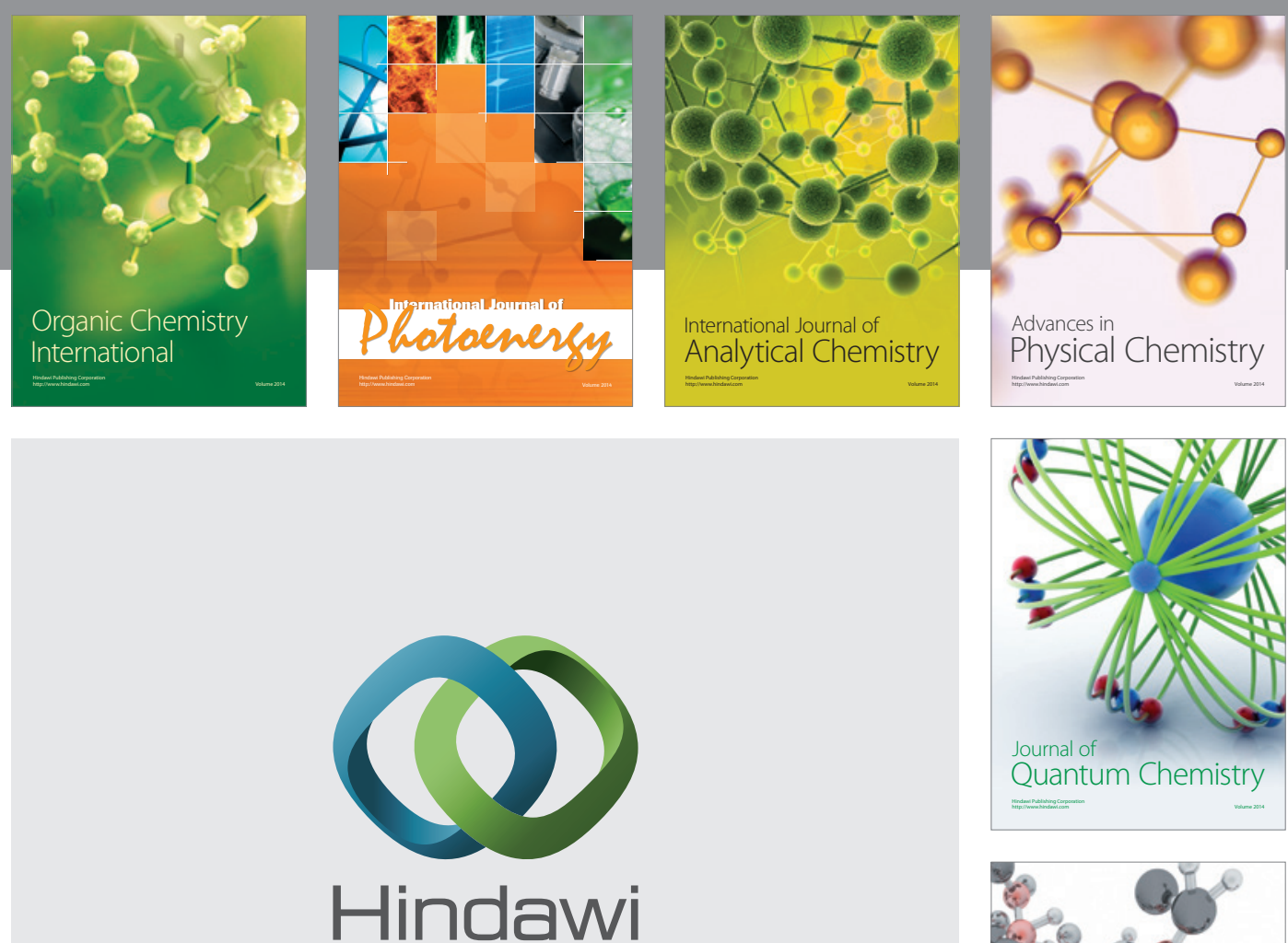

Submit your manuscripts at

http://www.hindawi.com

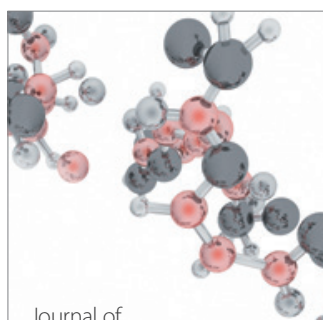

Analytical Methods

in Chemistry

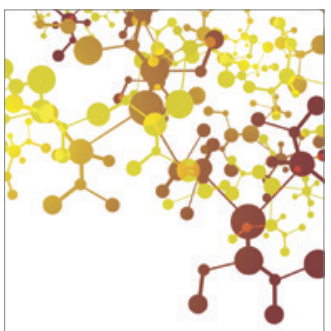

Journal of

Applied Chemistry

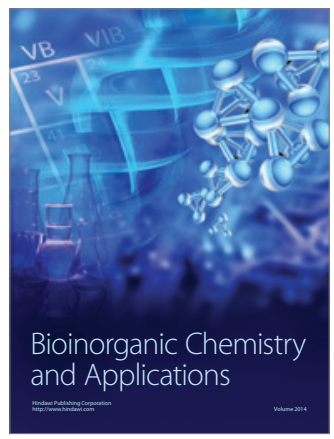

Inorganic Chemistry
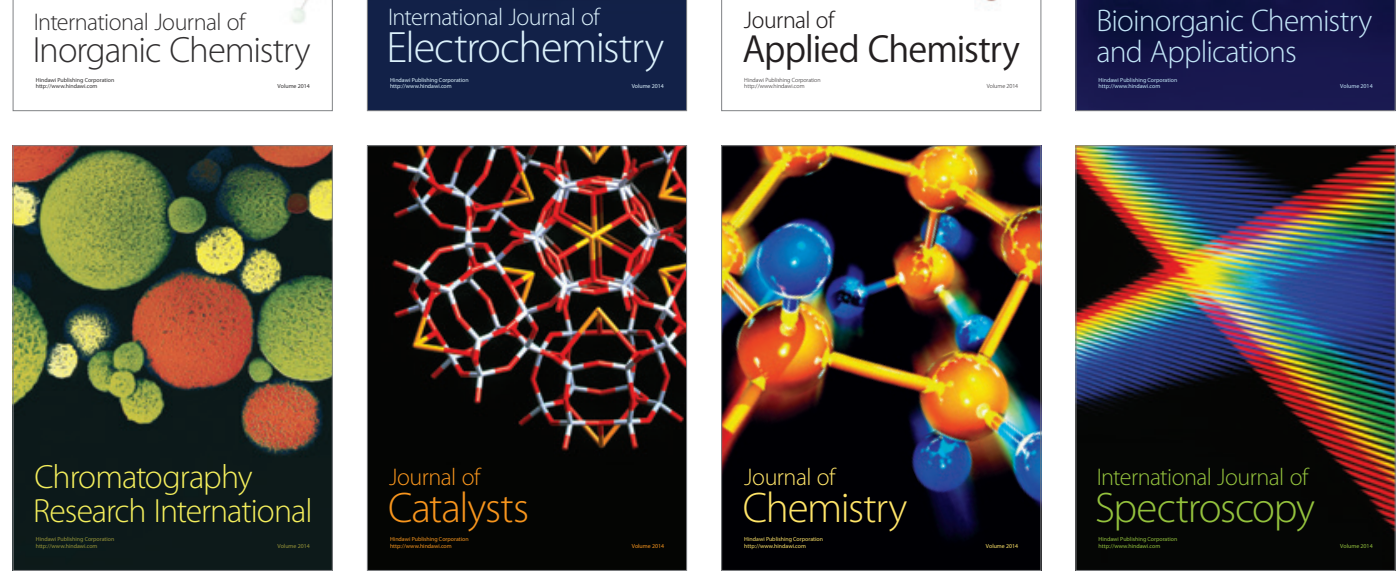